Journal of Social Sciences 8 (2): 189-195, 2012

ISSN 1549-3652

(C) 2012 Science Publications

\title{
Demotivating Factors for English Language Learning Among University Students
}

\author{
${ }^{1}$ Reyhaneh Ghadirzadeh, \\ ${ }^{1}$ Fariba Pourabolfathe Hashtroudi and ${ }^{2}$ Omid Shokri \\ ${ }^{1}$ Department of English Language, Faculty of Humanities, \\ Saveh Branch, Islamic Azad University, Saveh, Iran \\ ${ }^{2}$ Department of Education and Psychology, Faculty of Humanities, \\ Shahid Beheshti University, Tehran, Iran
}

\begin{abstract}
Problem statement: Demotivation is a relatively new issue in the field of second/foreign Language (L2) learning motivation. Recognizing and removing barriers can have a marked effect on motivation and attention to learning in general and ESL/EFL learning in particular. Demotivating factors are essential factors which negatively influence the learner's attitudes and behaviors and hence lead to undesired learning outcomes. The purpose of the present study was to analyze the effective factors on demotivation for English language learning among a group of Iranian university students. Approach: To begin, 260 university students (150 males and 110 females) were selected through the multi-stage sampling method. Students completed the Persian version of the Demotivation Questionnaire for English Language Learning (DQELL). The principal component analysis was used to compute the DQELL's factorial validity and the multivariate analysis of variance was performed to compare more motivated and less motivated learners based on demotivation factors. Results: Through the principal axis factor analysis, five demotivation factors were extracted: (a) lack of perceived individual competence, (b) lack of intrinsic motivation, (c) inappropriate characteristics of teachers' teaching methods and course contents, (d) inadequate university facilities and (e) focus on difficult grammar. The results of multivariate analysis of variance showed statistically significant differences between the two groups for two factors (lack of perceived individual competence and lack of intrinsic motivation) while there were no statistically significant differences for the other three demotivating factors (inappropriate characteristics of teachers' teaching methods and course contents, inadequate university facilities and focus on difficult grammar). Conclusion: These findings suggest that internal forces cannot be ignored as demotivating factors when studying them among Iranian students.
\end{abstract}

Key words:Demotivation, learning motivation, language learning, Classic Test Theory (CTT), Multivariate Analysis of Variance (MANOVA)

\section{INTRODUCTION}

Different experimental evidences have shown that some English language learners lose their interest and motivation during the English language learning process (Falout and Maruyama, 2004; Ayako, 2004; Kikuchi and Sakai, 2009; Dornyei and Murphey, 2003; Falout et al., 2009). According to Dornyei (2001a), demotivation refers to the specific external forces that reduce or diminish the motivational basis of a behavioral intention or an ongoing action. Undoubtedly, studying the concept of demotivation will be of great importance for not only researchers but many teachers who see their learners becoming demotivated in their daily classrooms in different educational levels. Researchers may be curious about this issue because examining the cause of the demotivation lends support in understanding theories on motivation. And, teachers may want to understand the possible cause of their students' demotivation in order to try to avoid being the cause of demotivation. Many researchers in the L2 learning field, however, have only started to study on this topic fairly recently. However, some interested in studying the possible causes of demotivation among English language learners have focused on the important role of internal factors such as lack of self-confidence and negative

Corresponding Author: Reyhaneh Ghadirzadeh, Department of English Language, Faculty of Humanities, Saveh Branch, Islamic Azad University, Saveh, Iran 


\section{J. Social Sci., 8 (2): 189-195, 2012}

attitude within learners themselves in addition to external ones (Dornyei, 2001b; Kiwa, 2004; Falout and Maruyama, 2004; Kojima, 2004; Tsuchiya, 2006).

During the last decades, demotivation has often been studied in the area of "instructional communication" and academic lecture presentations in different countries (Zhang, 2007). Gorham and Christophel (1992) studied the role of factors related to classroom in the increase or decrease of bachelor degree students' demotivation. In that research, of 926 participants' responses, 399 students $(43 \%)$ stressed the role of factors related to teacher behavior like "Not knowledgeable; not in control of classroom; low credibility," "No sense of humor; loses temper; is a pessimist," "Boring; not dynamic; teacher is bored with class; unorganized lectures; unprepared," and "No office hours; not available for individual help" 330 other responses $(36 \%)$ concerned the structure/format factor. In this part, students focused on the important role of some factors like "physical classroom atmospherenegative (size of class, poor equipment; unattractive room)," "General organization of material-negative (text and lectures same, no relationship between text and lectures, too much reliance on videos/speakers, too rigid, makes material hard to grasp)," and "Dissatisfaction with grading and assignments; unclear instructions; irrelevant assignments; grading too hard or too easy; failure to perform well." Finally, 197 students (21\%) referred to the role of context factor. In this part, students focused on the points like "Dislike subject area; subject is boring or redundant; subject too difficult; not seen as relevant," "Time of day; length of class; sick of school; personal laziness; no challenge; poor health; don't feel I belong to college," and "Too many demands besides class." Gorham and Christophel (1992) found out that among different factors, teacher behavior had the most important role in students' demotivation. Similarly, the results of Zhang (2007) study showed that students in China, Germany, Japan and America reported the most demotivating factor in their English language learning as teachers' incompetence.

In the field of language teaching, some researchers like and Ehrman and Dornyei (1998), have studied demotivation systematically. Dornyei (1994) studying the possible factors of demotivation among English language learners focused on the role of effective factors at three levels of language, learner and learning situation. The results of her study showed that the most important elements for the learners' demotivation concerned the learner levels and learning situation levels. Learner level problems (e.g., lack of self-confidence, caused mostly by negative past experiences) and learning situation level problems (e.g., being placed into an inappropriate group for their level of English proficiency, lack of free choice, lack of skilled teachers and lack of constancy in language learning in a relaxed and pleasant atmosphere) were found to be the primary cause of the participants' demotivation.

Moreover, Dornyei (2001a) presented the following nine demotivating factors based on his studies about the possible factors of demotivation:

- Teachers' personalities, commitments, competence, teaching methods

- Inadequate school facilities (large class sizes, unsuitable level of classes or frequent change of teachers)

- Reduced self-confidence due to their experience of failure or lack of success

- Negative attitude toward the foreign language studied

- Compulsory nature of the foreign language study

- Interference of another foreign language that pupils are studying

- Negative attitude toward the community of the foreign language spoken

- Attitudes of group members

- Course books used in class

The results of a research conducted by Ikeno (2003) also showed that some of the demotivating factors among Japanese students were the lack of a sense of control over what one is learning, distrust in the ability of teachers, doubts about the character of teachers, a sense of classes being solely exam-oriented, feelings of inferiority about one's English ability and peers' negative attitude toward English learning.

In addition, Tsuchiya (2006) studying the effective factors on demotivation among some unsuccessful English language learners listed nine demotivators: teachers, classes, the compulsory nature of English study, a negative attitude toward the English community, a negative attitude toward English itself, reduced selfconfidence, negative group attitude, the lack of positive English speaking models and ways of learning.

Finally, Sakai and Kikuchi (2009) investigated six effective factors on demotivation based on the previous studies on demotivation:

Teachers: Teachers' attitude, teaching competence, language proficiency, personality and teaching style (Kiwa, 2004; Christophel and Gorham, 1995; Falout and Maruyama, 2004; Gorham and Christophel, 1992; Gorham and Millette, 1997; Ikeno, 2003; Kikuchi, 2009; Kikuchi and Sakai, 2007; Kojima, 2004; Tsuchiya, 2006; Zhang, 2007). 
Characteristics of classes: Course contents and pace, focus on difficult grammar or vocabulary, monotonous and boring lessons, a focus on university entrance exams and the memorization of the language (Kiwa, 2004; Christophel and Gorham, 1995; Falout and Maruyama, 2004; Gorham and Christophel, 1992; Gorham and Millette, 1997; Kikuchi, 2009; Kikuchi and Sakai, 2009; Kojima, 2004; Ikeno, 2003; Tsuchiya, 2006; Zhang, 2007).

Experiences of failure: Disappointment due to test scores, lack of acceptance by teachers and others and feeling unable to memorize vocabulary and idioms (Christophel and Gorham, 1995; Falout and Maruyama, 2004; Gorham and Christophel, 1992; Gorham and Millette, 1997; Kikuchi, 2009; Kikuchi and Sakai, 2009; Kojima, 2004; Ikeno, 2003; Tsuchiya, 2006).

Class environment: Attitude of classmates, compulsory nature of English study, friends' attitudes, inactive classes, inappropriate level of the lessons and inadequate use of school facilities such as not using audio-visual materials (Kiwa, 2004; Christophel and Gorham, 1995; Falout and Maruyama, 2004; Gorham and Christophel, 1992; Gorham and Millette, 1997; Kikuchi, 2009; Kikuchi and Sakai, 2009; Tsuchiya, 2006).

Class materials: Not suitable or uninteresting materials (e.g., too many reference books and/or handouts) (Kiwa, 2004; Christophel and Gorham, 1995; Falout and Maruyama, 2004; Gorham and Christophel, 1992; Gorham and Millette, 1997; Kikuchi, 2009; Kikuchi and Sakai, 2009; Kojima, 2004).

Lack of interest: Sense that English used at schools is not practical and not necessary little admiration toward English speaking people. (Christophel and Gorham, 1995; Falout and Maruyama, 2004; Gorham and Christophel, 1992; Gorham and Millette, 1997; Kojima, 2004; Ikeno, 2003; Tsuchiya, 2006)

Sakai and Kikuchi (2009), through an exploratory factor analysis of Demotivation Questionnaire of English Language Learning, extracted five demotivation factors: (a) Learning Contents and Materials, (b) Teachers' Competence and Teaching Styles, (c) Inadequate School Facilities, (d) Lack of Intrinsic Motivation and (e) Test Scores. The results showed that the Learning Contents and Materials and Test Scores factors were demotivating factors for many Japanese high school students, especially for less motivated learners. Contrary to what previous research suggested, Teachers' Competence and Teaching Styles was not a very strong cause of demotivation compared to Learning Contents and
Materials or Test Scores for both more and less motivated groups. This study also showed that both more and less motivated learners did not perceive Inadequate School Facilities as demotivating.

Accordingly, the present study follows two aims. First, it wants to investigate the possible factors of demotivation among Iranian English language learners. Second, it tries to compare more motivated students with less motivated ones in English language learning considering the possible factors of demotivation.

\section{MATERIALS AND METHODS}

Participants: The Participants of this research were 260 (150 males and 110 females) Bachelor degree students of engineering and human sciences in Islamic Azad University, Saveh Branch, Saveh, Iran. These participants were selected at three levels: (1) faculty, (2) educational group and (3) class, using the multistage cluster sampling method.

Demotivation questionnaire: Sakai and Kikuchi (2009), reviewing the results of previous studies about the possible demotivation factors, investigated six effective factors on demotivation. Then, they devised a demotivation questionnaire based on those effective factors. This questionnaire consists of 35 5-point Likert type items. In Sakai and Kikuchi (2009) study which aimed to examine the factorial structure of demotivation questionnaire, the results of exploratory factor analysis showed that demotivation questionnaire consisted of five factors: Learning Contents and Materials, Teachers' Competence and Teaching Styles, Inadequate School Facilities, Lack of Intrinsic Motivation and Test Scores. In the present study, based on another exploratory factor analysis, the five factors of Lack of Perceived Individual Competence, Lack of Intrinsic Motivation, Inappropriate Characteristics of Teachers' Teaching Methods and Course Contents, Inadequate University Facilities and Focus on Difficult Grammar were extracted whose Cronbach alpha coefficients were $0.84,0.82,0.76,0.74$ and 0.60 respectively.

The questionnaire also included one question about motivation to learn English: "How motivated are you to learn English?" The participants were required to choose one of the alternatives: 1: I have almost no motivation; 2: I have a little motivation; 3: I have moderate motivation; and 4: I have high motivation. Based on the responses to this question, the participants were divided into less motivated learners and more motivated learners. The participants who answered they had no or little motivation were considered as less motivated and those who answered they had moderate or high motivation were considered as more motivated students. 


\section{J. Social Sci., 8 (2): 189-195, 2012}

Research method: The present study is correlational. In this research, data analysis was done based on the Classic Test Theory (CTT). Preserving or deleting the items of questionnaire was performed using the statistical properties of factorial analysis. Reliability was calculated using Cronbach alpha coefficient formula. Validity of the questionnaire was also checked through factorial validity calculations (principal component analysis with oblimin rotation). Then, in order to compare the two more and less motivated groups based on the possible demotivation factors the Multivariate Analysis of Variance (MANOVA) was used.

Data collection and analysis: First of all, the voluntary participation of the subjects was checked through a solicitation statement. In addition, the purpose of the study was briefly explained to the participants focusing on the importance of "analysis of the possible factors of demotivation for English language learning". Then, all participants completed the questionnaires in groups. Considering the number of items, 15-20 min was allocated for the students to answer the questionnaires. Finally, after gathering the data, the data analysis was performed using the statistical software of SPSS.

\section{RESULTS}

Before performing the exploratory factor analysis, Kaiser-Meyer-Olkin measure of sampling adequacy index was calculated as 0.84 and by Bartlett's test of sphericity $(\mathrm{p}<0.001), \times 2(595 \mathrm{~N}=260)$ was equal to 2451.72 , indicating that the sample and correlational matrix were appropriate for this analysis. In line with Sakai and Kikuchi (2009) study, considering the correlation between the factors, to extract the factors, an oblimin rotation procedure was performed. In other words, in order to specify the most appropriate factors, considering the scree plot, Eigen value and variance percentage of each factor, the mentioned factors were extracted by principal component analysis and oblimin rotation.

In the present study, the results of exploratory factor analysis indicated that the five factors explained $47.84 \%$ of the general factor variance of demotivation in English language learning among students (Table 1). Moreover, the results of exploratory factor analysis of DQELL showed that from 35 items of the questionnaire, items 2, 19, 26 and 28 were omitted because their factor loadings were less than 0.4 .

Differences in demotivating factors between less motivated and more motivated learners: Before studying the results of the comparison between the two less and more motivated groups, the descriptive statistics for each possible factor of demotivation should be reported separately (Table 2 ).
Table 1:Statistical properties of DQELL using PC method for a 5factor structure

\begin{tabular}{|c|c|c|c|}
\hline Factor & $\begin{array}{l}\text { Eigen } \\
\text { Value }\end{array}$ & $\begin{array}{l}\text { Variance } \\
(\%)\end{array}$ & $\begin{array}{l}\text { Cumulative } \\
(\%)\end{array}$ \\
\hline Lack of perceived individual competence & 7.94 & 22.69 & 22.69 \\
\hline Lack of intrinsic motivation & 3.22 & 9.190 & 31.88 \\
\hline \multicolumn{4}{|l|}{ Inappropriate characteristics of teachers' } \\
\hline Teaching methods and course contents & 2.13 & 6.080 & 37.96 \\
\hline Inadequate university facilities & 1.80 & 5.150 & 43.10 \\
\hline Focus on difficult grammar & 1.66 & 4.740 & 47.84 \\
\hline
\end{tabular}

Table 2: Descriptive statistics for each factor

\begin{tabular}{llll}
\hline Factor & Group & M & SD \\
\hline Lack of perceived individual & More motivated & 19.76 & 7.77 \\
competence & Less motivated & 25.16 & 7.40 \\
Lack of intrinsic motivation & More motivated & 16.00 & 7.17 \\
& Less motivated & 21.68 & 6.24 \\
Inappropriate characteristics of & & & \\
teachers' teaching methods & More motivated & 21.07 & 6.88 \\
and course contents & Less motivated & 22.63 & 6.22 \\
Inadequate university facilities & More motivated & 18.53 & 2.66 \\
& Less motivated & 18.67 & 2.44 \\
Focus on difficult grammar & More motivated & 9.860 & 2.63 \\
& Less motivated & 9.920 & 2.61 \\
\hline
\end{tabular}

Then, to compare the mean scores of more and less motivated learners considering the multiple factors of demotivation for English language learning, a multivariate analysis of variance was performed. In this statistical method, on the first stage, existence or lack of existence of the significance of linear combination of dependent variables will be investigated considering the independent variable of the groups. On the second stage, after dividing the dependent variables, they will be analyzed at independent variable levels by using some one-way analyses of variance. In other words, results of this study show whether the independent variable has an effect on the linear combination of dependent variables or not (Giles, 2002). In this research, dependent variables include multiple factors of demotivation.

Before performing MANOVA, it is necessary to investigate the hypotheses of normality of score dispersion through the significance level of Kolmogorov-Smirnov Test and the homogeneity of variance-covariance matrixes by Box's M statistics (Dancey and Reidy, 2004). In this study, normality hypothesis of score dispersion of each dependent variable and the hypothesis of variance-covariance homogeneity was investigated and confirmed.

As mentioned before, in this research, in order to investigate the effect of group on dependent, MANOVA was used. To answer the research questions, the researchers, in line withTabachnic and Fidel's opinions (1997; quoted from Dancey and Reidy, 2004), from among four statistics (Pillai's Trace, Wilks' Lambda, Hotelling's Trace and Roy's Largest Root), selected Wilks' Lambda to calculate F. 


\section{J. Social Sci., 8 (2): 189-195, 2012}

Table 3:Summary of the one-way analysis of variance to show the significance of each dependent variable in dividing the two groups

\begin{tabular}{llll}
\hline Factor group & $\mathrm{F}(\mathrm{df})$ & $\mathrm{P}$ & $\eta^{2}$ \\
\hline Lack of perceived individual competence & $25.20(1)$ & $0.000^{*}$ & 0.12 \\
Lack of intrinsic motivation & $32.90(1)$ & $0.000^{*}$ & 0.15 \\
Inappropriate characteristics of teachers & & & \\
Teaching methods and course contents & $3.520(1)$ & 0.062 & 0.02 \\
Inadequate university facilities & $0.025(1)$ & 0.875 & 0.00 \\
Focus on difficult grammar & $0.002(1)$ & 0.967 & 0.00 \\
\hline
\end{tabular}

The results of Multivariate Analysis of Variance of general and specific schools of thought using Wilks' Lambda showed that there's a significant difference between the two groups considering the linear combination of dependent variables $(\mathrm{F}(5,186)=$ $\left.8.45, \mathrm{p}=0.000, \eta=0.82, \eta^{2}=0.19\right)$. Regarding the significance of linear combination of dependent variables on variable levels of group, the report of post hoc one-way analysis of variance tests seems necessary in order to investigate the significance or insignificance of the share of each dependent variable. (Brace et al., 2006). As shown in Table 3, the analysis of each dependent variable using Benferroni adjusted alpha level (0.008) revealed that the factors "Lack of perceived individual competence" $(\mathrm{F}(1,190)=25.20$, $\left.\mathrm{p}<0.000, \quad \eta^{2}=0.12\right)$ and "Lack of intrinsic motivation" $\left(\mathrm{F}(1,190)=32.90, \mathrm{p}<0.000, \eta^{2}=0.15\right)$ had significant shares in dividing the two groups. However, "Inappropriate characteristics of teachers' teaching methods and course contents" $(\mathrm{F}(1,190)=$ $\left.3.52, \mathrm{p}=0.062, \eta^{2}=0.02\right)$, "Inadequate university facilities" $\left(\mathrm{F}(1,190)=0.025, \mathrm{p}=0.875, \eta^{2}=0.000\right)$ and "Focus on difficult grammar" $(\mathrm{F}(1,190)=0.002, \mathrm{p}$ $\left.=0.967, \eta^{2}=0.000\right)$ had generally insignificant roles.

\section{DISCUSSION}

In this study, the first research question asked what the main demotivating factors for English language learning among Iranian students were. In line with Sakai and Kikuchi (2009) study, the result of principal component analysis with oblimin rotation showed that DQELL consisted of five factors: "Lack of perceived individual competence", "Lack of intrinsic motivation", "Inappropriate characteristics of teachers' teaching methods and course contents", "Inadequate university facilities" and "Focus on difficult grammar". In other words, in this study, in line with the findings of Dornyei (2001a) and Sakai and Kikuchi (2009), structural model of demotivation includes intrinsic-extrinsic factors. The findings of the present study, in line with the findings of Sakai and Kikuchi (2009) study supported the multidimensional nature of demotivation for English language learning construct among Iranian students by repeating the 5-factor structure of DQELL.

In addition, the similarity between the findings of the present study and those of Sakai and Kikuchi (2009) study about the factorial structure of DQELL shows that the factors constituting the basic model of demotivation for English language learning, in Iranian and Japanese samples, follow the same model. In other words, the similarity between the results of the present study and Sakai and Kikuchi (2009), considering the structural dimension of DQELL, shows that the basic structure and causal-theoretical systems of demotivation for English language learning in Iranian and Japanese samples follow general principles.

The second question of this study was: "Is there any significant difference between the two groups of more and less motivated students for English language learning?" In this research, in line with Sakai and Kikuchi (2009) findings, the results of multivariate analysis of variance showed that the two groups of more and less motivated students for English language learning were statistically different only in intrinsic factors of demotivation including Lack of Perceived Individual Competence and Lack of Intrinsic Motivation. In other words, in the present study, there was no significant difference between the two groups of more and less motivated students for English language learning considering the extrinsic factors of demotivation including Inappropriate Characteristics of Teachers' Teaching Methods and Course Contents, Inadequate University Facilities and Focus on Difficult Grammar.

Although the intrinsic factors for demotivation including Lack of Perceived Individual Competence and Lack of Intrinsic Motivation were effective in dividing the two groups of more and less motivated students, comparison of the mean scores of demotivators in Table 2, shows that perceiving the importance of those factors in order to investigate the motivational status of learners in different groups follows the similar model.

In the present research, a hypothesized explanation for clarifying the reason for the importance of intrinsic factors of demotivation compared to extrinsic factors in dividing the two groups of more and less motivated students is that perhaps in Iranian sample, considering English language learning, the feedback and judgment of important others like parents, teachers and friends about learners' operation focuses on the intrinsic characteristics of individuals. In other words, the attributive model of important others about the reasons of defeat and victory experiences of individuals in educational contexts constitutes the attributive contents of individuals for explanation of their operation. Therefore, stressing too much on the role of intrinsic factors in explaining and predicting individuals' experiences model in educational contexts causes the role of effective extrinsic factors to seem less important. 
The findings of the present study should be interpreted considering its limitations. It should be stated that some of the limitations of this study limits the generalization of its results. Some of these limitations are as follow. First, using self-report devices instead of studying the real behavior may encourage the participants to use methods based on social confirmation and avoiding notoriety related to Lack of Perceived Individual Competence. In other words, in order to confirm the self-report scales behavioral observance and the other clinical indices were not used. Second, to find the students' motivational status, they were asked to tick their motivation level on a multiplechoice item. Therefore, it is suggested that in the next studies in order to investigate the relation between the motivational status and possible factors of demotivation among learners, a more valid measuring device be used to estimate the motivation level of learners more carefully. Third, although the participants of this research include male and female students, studying the demotivation experiences model in two sexes was not considered by the researchers. Therefore it is suggested that the role of sex be considered in explaining the changeability of demotivation scores.

Although the results of this study in line with Sakai and Kikuchi (2009) study is based on the factorial analysis of DQELL as a 35-item device for measuring the concept of demotivation, the efforts of the researchers of the present study for showing the effective factors on demotivation among Iranian students and comparing the model of these experiences among the more and less motivated students for English language learning play an important role in understanding the complexity of the demotivation factors for English language learning among students in different cultural contexts.

\section{CONCLUSION}

These findings suggest that internal forces cannot be ignored as demotivating factors when studying them among Iranian students

\section{REFERENCES}

Ayako, H., 2004. Student demotivation in the foreign language classroom. Takushoku Langu. Stud., 107: 119-136.

Brace, N., R. Kemp and R. Snelgar, 2006. SPSS for Psychologists: A Guide to Data Analysis Using SPSS for WINDOWS (Versions 12 and 13). 3rd Edn., Routledge, ISBN-10: 0805860851, pp: 450.

Christophel, D.M. and J. Gorham, 1995. A test-retest analysis of student motivation, teacher immediacy and perceived sources of motivation and demotivation in college classes. Commu. Educ., 44: 292-306. DOI: 10.1080/03634529509379020
Dancey, C. and J. Reidy, 2004. Statistics Without Maths for Psychology with Psychology Dictionary. 1st Edn., Pearson Education, ISBN-10: 0582895936.

Dornyei, Z. and T. Murphey, 2003. Group Dynamics in the Language Classroom. 1st Edn., Cambridge University Press, Cambridge, ISBN-10: 0521529719, pp: 191.

Dornyei, Z., 1994. Motivation and motivating in the foreign language classroom. Modern Langu. J., 78: 273-284. DOI: $\quad 10.1111 / \mathrm{j} .1540-$ 4781.1994.tb02042.x

Dornyei, Z., 1998. Demotivation in foreign language learning. Seattle, WA.

Dornyei, Z., 2001a. Teaching and Researching Motivation. 1st Edn., Longman, Harlow, ISBN-10: 0582382386, pp: 295.

Dornyei, Z., 2001b. Motivational Strategies in the Language Clasroom. 9th Edn., Cambridge University Press, Cambridge, ISBN-10: 9780521793773, pp: 155.

Ehrman, M.E. and Z. Dornyei, 1998. Interpersonal Dynamics in Second Language Education: The Visible and Invisible Classroom. 1st Edn., Sage Publications, Thousand Oaks, California, ISBN-10: 0761907211, pp: 329.

Falout, J. and M. Maruyama, 2004. A comparative study of proficiency and learner demotivation. Langu. Teacher, 28: 3-3.

Falout, J., J. Elwood and M. Hood, 2009. Demotivation: Affective states and learning outcomes. System, 37: 403-417. DOI: 10.1016/j.system.2009.03.004

Giles, D.C., 2002. Advanced Research Methods in Psychology. 1st Edn., Routledge, ISBN-10: 0415227712, pp: 351.

Gorham, J. and D.M. Christophel, 1992. Students' perceptions of teacher behaviors as motivating and demotivating factors in college classes. Commun. Q., $40: \quad 239-252 . \quad$ DOI: 10.1080/01463379209369839

Gorham, J. and D.M. Millette, 1997. A comparative analysis of teacher and student perceptions of sources of motivation and demotivation in college classes. Commun. Educ., 46: 245-261. DOI: 10.1080/03634529709379099

Ikeno, O., 2003. Motivating and demotivating factors in foreign language learning: A preliminary investigation. Ehime University J. English Educ. Res., 2: 1-19.

Kikuchi, K. and H. Sakai, 2009. Japanese learners' demotivation to study English: A survey study. JALT J., 31: 183-204. 
Kikuchi, K., 2009. Listening to our learners' voices: What demotivates Japanese high school students? Langu. Teach. Res., 13: 453-471. DOI: $10.1177 / 1362168809341520$

Kiwa, A., 2004. What 'demotivates' language learners? Qualitative study on demotivational factors and learners' reactions. Bull. Toyo Gakuen Univ., 12: 39-47.

Kojima, S., 2004. English learning demotivation in Japanese EFL students: Research in demotivational patterns from the qualitative research results of three different types of high schools. Unpublished Master Thesis. Kwansei Gakuin University, Hyogo, Japan,
Sakai, H. and K. Kikuchi, 2009. An analysis of demotivators in the EFL classroom. System, 37: 57-69. DOI: 10.1016/j.system.2008.09.005

Tsuchiya, M., 2006. Profiling of lower achievement English learners at college in terms of demotivating factors. Annual Rev. English Langu. Educ. Japan, 17: 171-180.

Zhang, Q., 2007. Teacher misbehaviors as learning demotivators in college classrooms: A crosscultural investigation in China, Germany, Japan and the United States. Commun. Educ., 56: 209227. DOI: $10.1080 / 03634520601110104$ 